\title{
The impact of old age on cancer-specific and non-cancer-related survival following elective potentially curative surgery for Dukes
} \section{A/B colorectal cancer}

\author{
DC McMillan ${ }^{*, I}$, DJ Hole, and CS McArdle' \\ 'University Department of Surgery, Faculty of Medicine, University of Glasgow, Glasgow GI 2 8QQ, UK; ${ }^{2}$ University Department of Public Health, Faculty \\ of Medicine, University of Glasgow, Glasgow GI 2 8QQ, UK
}

Previous studies have suggested that survival following surgery for colorectal cancer is poorer in the elderly. However, the findings were inconsistent and none of the studies adjusted for case mix. The aim of this study was to establish whether there were age-related differences in cancer (colorectal)-specific and non-cancer (colorectal)-related survival in patients undergoing elective potentially curative resection for Dukes stage A/B colorectal cancer. One thousand and forty three patients who underwent elective potentially curative resection for Dukes' A/B colorectal cancer between 1991 and 1994 in II hospitals in Scotland were included in the study. Ten year cancer-specific and non-cancer-related survival and the hazard ratios were calculated according to age groups ( $<64 ; 65-74 />74$ years). On follow-up 273 patients died of their cancer and 328 died of non-cancer-related causes. At 10 years, overall survival was $45 \%$, cancer specific was $70 \%$ and non-cancer-related survival was $64 \%$. On multivariate analysis of all factors, age (HR I.38, 95\% Cl I.I8- I.62, P<0.00I), sex (HR I.74, 95\% Cl I.36-2.23, P<0.00I), site (HR I.42, 95\% Cl I.II - I.8I, P<0.0I) and Dukes' stage (HR I.7I, I. I9-2.47, $P<0.01)$ were independently associated with cancer-specific survival. On multivariate analysis of all factors, age (HR 2.14, I.84-2.49, $P<0.001)$, sex (HR I.43, I.I $-1.79, P<0.01)$ and deprivation $(H R I .30,1.09-1.55, P<0.01)$ were independently associated with non-cancer-related survival. The results of this study show that increasing age impacts negatively both on cancer-specific and non-cancer-related survival following elective potentially curative resection for node-negative colorectal cancer. However, the effect of increasing age is greater on the non-cancer-related survival. These results suggest that cancer-specific and non-cancer-related mortality should be considered separately in survival analysis of these cancer patients.

British Journal of Cancer (2008) 99, 1046- 1049. doi:I0.1038/sj.bjc.6604669 www.bjcancer.com

Published online 16 September 2008

(c) 2008 Cancer Research UK

Keywords: colorectal cancer; age; elective; curative surgery; survival

Colorectal cancer is the second commonest cause of cancer death in Western Europe and North America. Many patients have evidence of locally advanced or metastatic disease at the time of initial presentation. Even in those undergoing apparently curative resection, only half survive for 5 years (McArdle and Hole, 2002a).

It has long been recognised that there are a number of factors, in addition to pathological stage, which contribute to poor outcome following potentially curative surgery for colorectal cancer. Age (Mulcahy et al, 1994; Shankar and Taylor, 1998; Colorectal Cancer Collaborative Group, 2000), gender (McArdle et al, 2003), deprivation (Hole and McArdle, 2002), tumour site (McArdle and Hole, 2002b), emergency presentation (McArdle and Hole, 2004a) and specialisation (McArdle and Hole, 2004b) have been shown to impact on long-term survival in these patients.

However, whether old age is associated with poorer survival, independent of these factors, remains unclear. The aim of this

*Correspondence: Dr DC McMillan, University Department of Surgery, Royal Infirmary, Glasgow G3I 2ER, UK;

E-mail: d.c.mcmillan@clinmed.gla.ac.uk

* David J Hole died on 26 March 2007.

Received 6 June 2008; revised 6 August 2008; accepted 22 August 2008; published online 16 September 2008 study was to establish whether there were age-related differences in cancer (colorectal)-specific and non-cancer (colorectal)-related survival in patients undergoing elective potentially curative resection for Dukes stage A/B colorectal cancer.

\section{PATIENTS AND METHODS}

One thousand and forty three patients who underwent an elective potentially curative resection for Dukes A/B colorectal cancer between 1 January 1991 and 31 December 1994 in 11 hospitals in the central belt of Scotland were included in the study. Information was abstracted from casenotes by two specially trained data managers. Details included age, sex, deprivation category, site of tumour, extent of tumour spread, the nature of surgery, postoperative mortality, Dukes' stage and adjuvant therapy. Data for 1991 and 1992 were collected retrospectively, and those for 1993 and 1994 were collected prospectively. There was no difference in baseline characteristics of the patients between the two periods.

The extent of deprivation was defined using the Carstairs Index (Carstairs and Morris, 1991), an area-based measure derived from the 1991 census data based on the postcode of residents at diagnosis. Carstairs divides the scores into a seven-point 
scale ranging from most affluent (category 1) to most deprived (category 7).

Tumours were classified according to the site colon or rectum. The extent of tumour spread was assessed by conventional Dukes' classification based on histological examination of the resected specimen.

Patients were deemed to have had a curative resection if the surgeon considered that there was no macroscopic residual tumour once resection had been completed.

Individual surgeons were defined as specialists or non-specialists by a panel of six senior consultants and one of the authors (CSMcA). Two of the six consultants were specialist colorectal surgeons from teaching hospitals and four were district general hospital consultants. These assessments were made without the knowledge of the outcome and before any analysis was performed.

The approval was obtained for information on date and cause of death to be checked with that received by the cancer registration system through linkage with the Registrar General (Scotland). Deaths up to the end of 2003 have been included in the analysis, providing an average length of follow-up of 11 years (minimum 9 years, maximum 13 years).

\section{Statistical analysis}

The percentages of patients surviving 10 years were calculated using the Kaplan-Meier technique. Comparison of the association between age and other variables was made using the $\chi^{2}$ test or a $\chi^{2}$ for trend where appropriate. The effect of age on cancer- and non-cancer-related survival was examined using Cox's proportional hazards model. Analysis was performed using the SPSS software package (SPSS Inc., Chicago, IL, USA).

\section{RESULTS}

Of the 1043 patients included in the analysis, 33\% were aged 75 years or over, $21 \%$ were socioeconomically deprived, $59 \%$ had colonic tumours and $82 \%$ had Dukes' B disease at the time of surgery. Two hundred and seventy five (26\%) patients were treated by a specialist surgeon. Three percent of patients received adjuvant therapy.

The baseline characteristics of the patients included in the study are shown in Table 1. With increasing age there was an increase in the proportion of patients who had colonic tumours $(P<0.001)$. Few patients over the age of 74 years received adjuvant therapy $(P<0.001)$.

Two hundred and seventy three patients died of their cancer and 328 died of non-cancer-related causes (Table 2). Of the non-cancer-related deaths, $212(65 \%)$ patients died of cardiovascular or respiratory disease. At 10 years, overall survival was $45 \%$, cancer specific was $70 \%$ and non-cancer-related survival was $64 \%$. An increased proportion of cancer deaths at 10 years was associated with increased Dukes' stage $(P<0.05)$ and nonspecialist surgeons $(P<0.10)$. An increased proportion of noncancer-related deaths at 10 years was associated with older age $(P<0.001)$, female gender $(P<0.05)$ and deprivation $(P<0.10)$.

On univariate analysis, age $(P<0.01)$, sex $(P<0.001)$, site $(P<0.05)$ and Dukes' stage $(P<0.01)$ were significantly associated with cancer-specific survival (Table 3 ). On multivariate analysis of all factors, age (HR 1.38, 95\% CI 1.18-1.62, $P<0.001$ ), sex (HR 1.74, 95\% CI $1.36-2.23, P<0.001$ ), site (HR $1.42,95 \%$ CI $1.11-1.81, P<0.01$ ) and Dukes' stage (HR 1.71, 1.19-2.47, $P<0.01$ ) were independently associated with cancer-specific survival.

On univariate analysis, age $(P<0.001)$, sex $(P<0.05)$, deprivation $(P<0.01)$ and adjuvant therapy $(P<0.10)$ were significantly associated with non-cancer-related survival (Table 4). On multivariate analysis of all factors, age (HR 2.14, 1.84-2.49, $P<0.001$ ), sex (HR 1.43, 1.15-1.79, $P<0.01$ ) and deprivation (HR 1.30, $1.09-1.55, P<0.01)$ were independently associated with noncancer-related survival.
Table I Baseline characteristics of patients undergoing elective curative resection for Dukes A/B colorectal cancer by age $(n=1043)$

\begin{tabular}{|c|c|c|c|c|}
\hline & \multicolumn{3}{|c|}{ Age (years) } & \multirow[b]{2}{*}{$P$-value } \\
\hline & $\begin{array}{c}<64 \text { years } \\
n=305(29 \%)\end{array}$ & $\begin{array}{c}65-74 \text { years } \\
n=398(38 \%)\end{array}$ & $\begin{array}{c}>74 \text { years } \\
n=340(33 \%)\end{array}$ & \\
\hline Female & | 43 (47\%) & $186(47 \%)$ & I $84(56 \%)$ & \\
\hline Male & 162 (53\%) & $212(53 \%)$ & $156(46 \%)$ & 0.061 \\
\hline \multicolumn{5}{|l|}{ Depcat score } \\
\hline 1,2 & $53(17 \%)$ & $70(18 \%)$ & $69(20 \%)$ & \\
\hline $3,4,5$ & $191(63 \%)$ & $245(62 \%)$ & 201 (59\%) & \\
\hline 6,7 & $61(20 \%)$ & $83(21 \%)$ & $70(21 \%)$ & 0.625 \\
\hline \multicolumn{5}{|l|}{ Site } \\
\hline Colon & I 60 (52\%) & $228(57 \%)$ & $223(66 \%)$ & \\
\hline Rectum & 145 (48\%) & 170 (43\%) & 117 (37\%) & $<0.001$ \\
\hline \multicolumn{5}{|l|}{ Dukes' stage } \\
\hline$A$ & $52(17 \%)$ & $76(19 \%)$ & $56(17 \%)$ & \\
\hline B & $253(83 \%)$ & $322(81 \%)$ & 284 (83\%) & 0.822 \\
\hline \multicolumn{5}{|l|}{ Specialisation } \\
\hline Specialist & $76(25 \%)$ & 104 (27\%) & $95(28 \%)$ & \\
\hline Non-specialist & 223 (75\%) & 288 (73\%) & $240(72 \%)$ & 0.402 \\
\hline \multicolumn{5}{|l|}{ Adjuvant therapy } \\
\hline Yes & $15(5 \%)$ & $16(4 \%)$ & $3(1 \%)$ & \\
\hline No & 290 (95\%) & 382 (96\%) & 337 (99\%) & $<0.001$ \\
\hline
\end{tabular}

Table 2 Baseline characteristics of patients undergoing elective curative resection for Dukes A/B colorectal cancer-by-cancer and non-cancer death after 10 years follow-up

\begin{tabular}{|c|c|c|c|}
\hline & $\begin{array}{l}\text { Cancer deaths } \\
(n=273)\end{array}$ & $\begin{array}{c}\text { Non-cancer } \\
\text { deaths }(n=328)\end{array}$ & $P$-value \\
\hline \multicolumn{4}{|l|}{ Age } \\
\hline$<64$ years & $68(25 \%)$ & $42(13 \%)$ & \\
\hline $65-74$ years & $109(40 \%)$ & $129(39 \%)$ & \\
\hline$>74$ years & 96 (35\%) & 157 (48\%) & $<0.001$ \\
\hline Female & $104(38 \%)$ & $153(47 \%)$ & \\
\hline Male & $169(62 \%)$ & $175(53 \%)$ & 0.035 \\
\hline \multicolumn{4}{|l|}{ Depcat score } \\
\hline 1,2 & 53 (19\%) & 45 (14\%) & \\
\hline $3,4,5$ & $167(62 \%)$ & 206 (63\%) & \\
\hline 6,7 & 53 (19\%) & 77 (24\%) & 0.052 \\
\hline \multicolumn{4}{|l|}{ Site } \\
\hline Colon & | 48 (54\%) & 192 (59\%) & \\
\hline Rectum & $125(46 \%)$ & $136(41 \%)$ & 0.287 \\
\hline \multicolumn{4}{|l|}{ Dukes' stage } \\
\hline A & $34(13 \%)$ & 61 (19\%) & \\
\hline B & 239 (87\%) & 267 (81\%) & 0.040 \\
\hline \multicolumn{4}{|l|}{ Specialisation } \\
\hline Specialist & 61 (23\%) & $94(27 \%)$ & \\
\hline Non-specialist & 209 (77\%) & $226(71 \%)$ & 0.062 \\
\hline \multicolumn{4}{|l|}{ Adjuvant therapy } \\
\hline Yes & $10(4 \%)$ & $6(2 \%)$ & \\
\hline No & 263 (96\%) & 322 (98\%) & 0.165 \\
\hline
\end{tabular}

The relationship between age and the hazard ratios for cancer and non-cancer-related survival in patients with Dukes' A/B disease colon and rectum cancer is shown in Table 5. Compared 
Table 3 The relationship between clinicopathological characteristics and cancer-specific survival in patients undergoing elective curative resection for Dukes A/B colorectal cancer: univariate and multivariate analysis

\begin{tabular}{|c|c|c|c|c|c|}
\hline & Patients $(n=1043)$ & \multicolumn{2}{|c|}{ Univariate analysis } & \multicolumn{2}{|c|}{ Multivariate analysis } \\
\hline Sex (female/male) & $513 / 530$ & $1.75(1.37-2.23)$ & $<0.001$ & $1.74(1.36-2.23)$ & $<0.001$ \\
\hline Deprivation $(1-2 / 3-5 / 6-7)^{a}$ & 192/637/214 & $0.98(0.81-1.19)$ & 0.840 & & 0.322 \\
\hline Site (colon/rectum) & $611 / 432$ & $1.28(1.01-1.62)$ & 0.044 & $1.42(1.11-1.81)$ & 0.006 \\
\hline Dukes' stage (A/B) & $184 / 859$ & $1.70(1.19-2.44)$ & 0.004 & $1.71(1.19-2.47)$ & 0.004 \\
\hline
\end{tabular}

andividual deprivation categories were used in the statistical analysis.

Table 4 The relationship between clinicopathological characteristics and non-cancer survival in patients undergoing elective curative resection for Dukes A/B colorectal cancer: univariate and multivariate analysis

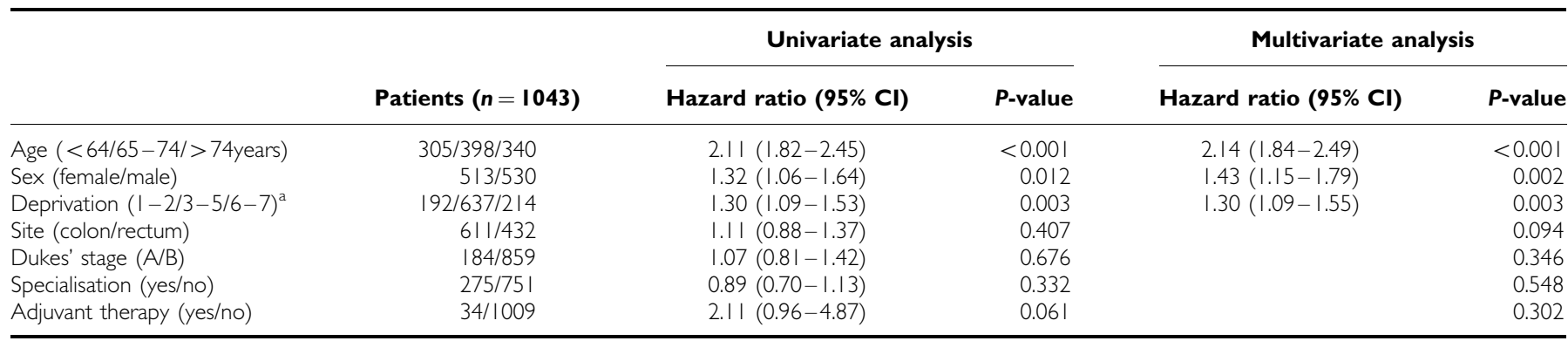

Individual deprivation categories were used in the statistical analysis.

Table 5 Hazard ratios for cancer-specific and non-cancer survival at 10 years in patients undergoing elective curative resection for Dukes A/B colorectal cancer by age

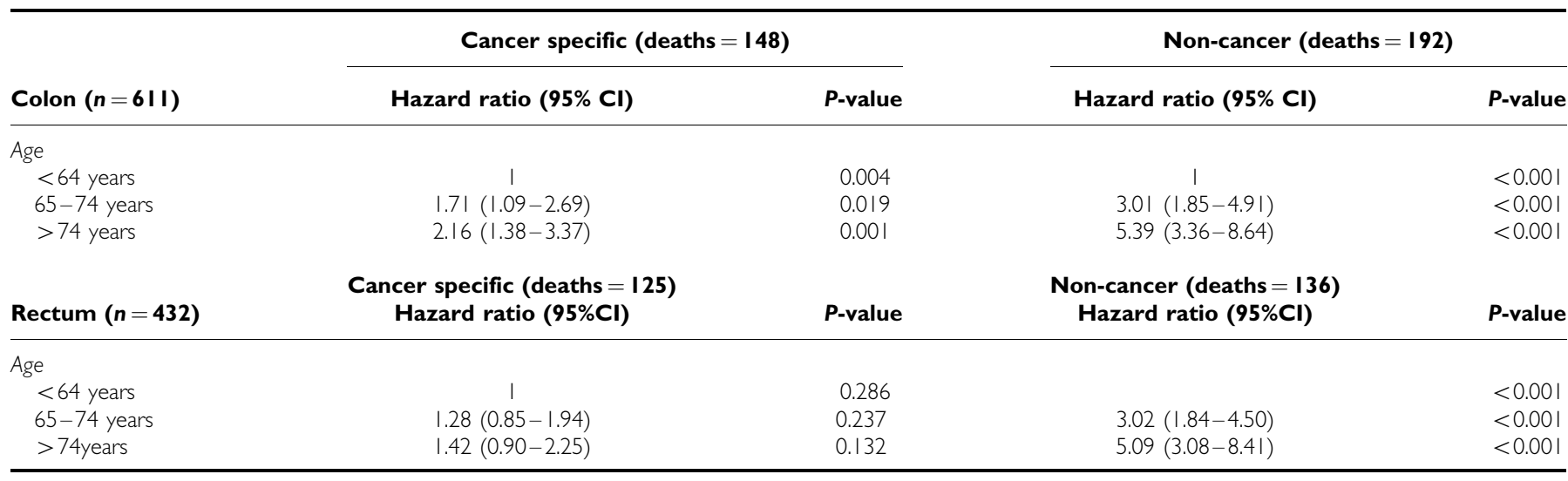

with patients under the age of 64 years who had colonic tumours, those patients over the age of 74 years had a hazard ratio of $2.2(P<0.01)$ and $5.4(P<0.001)$ for cancer and non-cancer-related survival, respectively. Compared with patients under the age of 64 years who had rectal tumours, those patients over the age of 74 years had a hazard ratio of $5.1(P<0.001)$ for non-cancerrelated survival.

\section{DISCUSSION}

The results of this study show that, in patients undergoing elective potentially curative surgery for Dukes' A/B colorectal cancer, with 10-year follow-up, more patients die of intercurrent disease, in particular cardiovascular or respiratory disease, than die of cancer. Increasing age, 75 years and over, impacted on cancer-related and non-cancer-related survival. Although, it was notable that the effect on non-cancer-related survival was approximately twice that of cancer-related survival.

Given that colorectal cancer is a common cancer and that large numbers of patients undergoing elective potentially curative resection will die of intercurrent comorbid disease, the use of overall survival as an end point may give misleading results. Therefore, future studies on these patients should specify the associations between factors and cancer-specific survival and non-cancer-related survival separately to establish whether the 
factor impacts equally on cancer-specific and non-cancer-related survival.

The results of this study have a number of important implications. First, with the introduction of screening programmes for colorectal cancer and the consequent increase in early stage disease, it is likely that the issue of age-related comorbid death will become a major issue in these patients. If this were proven to be the case, it would be important that within screening programmes for colorectal cancer, patients should also be screened for the presence of comorbid disease. For example, in patients aged of 75 years and over undergoing potentially curative resection for node-negative colorectal cancer, it would be important not only to treat the cancer, but also the comorbid disease, in particular it would appear from this study that this is cardiovascular or respiratory disease.

In the context of this study, it is of interest that a strong association between colorectal cancer and vascular disease has been reported (Chan et al, 2006, 2007). This may be because of the shared environmental risk factors such as age, smoking, diabetes mellitus and obesity (Giovannucci and Martínez, 1996; Larsson et al, 2005; McMillan et al, 2006). It has also been hypothesised that these diseases develop through a common pathway of chronic inflammatory disease (Chan et al, 2006, 2007). Indeed, there is evidence that such environmental factors are directly associated with C-reactive protein concentrations, the prototypical marker of the systemic inflammatory response, in apparently healthy subjects (Koenig et al, 1999; Hutchinson et al, 2000; Chenillot et al, 2000: Wong et al, 2001). However, it remains to be determined whether the systemic inflammatory response impacts equally on cancerspecific and non-cancer-related survival in patients undergoing potentially curative surgery for colorectal cancer.

In summary, the results of this study show that although age impacts both on cancer-specific and non-cancer-related survival following elective potentially curative resection for node-negative colorectal cancer, the effect is greater on non-cancer-related survival. These results suggest that cancer-specific and noncancer-related deaths should be considered separately in survival analysis of these patients.

\section{ACKNOWLEDGEMENTS}

We thank the surgeons who participated in the study and Heather Wotherspoon and Janette Stevenson, who collected the baseline data. We also thank the Clinical Resource and Audit Group (CRAG), Scottish Home and Health Department, Scotland who funded the collection of the baseline data. This study was supported by Clinical Resource and Audit Group (CRAG), Chief Scientist Office, Scotland.

\section{REFERENCES}

Carstairs V, Morris R (1991) Deprivation and health in scotland. Aberdeen University Press: Aberdeen

Chan AO, Jim MH, Lam KF, Morris JS, Siu DC, Tong T, Ng FH, Wong SY, Hui WM, Chan CK, Lai KC, Cheung TK, Chan P, Wong G, Yuen MF, Lau YK, Lee S, Szeto ML, Wong BC, Lam SK (2007) Prevalence of colorectal neoplasm among patients with newly diagnosed coronary artery disease. JAMA 298: $1412-1419$

Chan AO, Lam KF, Tong T, Siu DC, Jim MH, Hui WM, Lai KC, Yuen MF, Lam SK, Wong BC (2006) Coexistence between colorectal cancer/ adenoma and coronary artery disease: results from 1382 patients. Aliment Pharmacol Ther 24: 535-539

Chenillot O, Henny J, Steinmetz J, Herbeth B, Wagner C, Siest G (2000) High sensitivity $\mathrm{C}$-reactive protein: biological variations and reference limits. Clin Chem Lab Med 10: 1003-1011

Colorectal Cancer Collaborative Group (2000) Surgery for colorectal cancer in elderly patients: a systematic review. Lancet 356(9234): 968-974

Giovannucci E, Martínez ME (1996) Tobacco, colorectal cancer, and adenomas: a review of the evidence. J Natl Cancer Inst 88: 1717-1730

Hole DJ, McArdle CS (2002) Impact of socioeconomic deprivation on outcome after surgery for colorectal cancer. Br J Surg 89: 586-590

Hutchinson WL, Koenig W, Frohlich M, Sund M, Lowe GD, Pepys MB (2000) Immunoradiometric assay of circulating C-reactive protein: agerelated values in the adult general population. Clin Chem 7: 934-938

Koenig W, Sund M, Frohlich M, Fischer HG, Lowel H, Doring A, Hutchinson WL, Pepys MB (1999) C-reactive protein, a sensitive marker of inflammation, predicts future risk of coronary heart disease in initially healthy middle-aged men: results from the MONICA (Monitoring Trends and Determinants in Cardiovascular Disease) Augsburg Cohort Study, 1984-1992. Circulation 99: $237-242$

Larsson SC, Orsini N, Wolk A (2005) Diabetes mellitus and risk of colorectal cancer: a meta-analysis. J Natl Cancer Inst 97: 1679- 1687

McArdle CS, Hole DJ (2002a) Outcome following surgery for colorectal cancer: analysis by hospital after adjustment for case-mix and deprivation. Br J Cancer 86: $331-335$

McArdle CS, Hole DJ (2002b) Outcome following surgery for colorectal cancer. Br Med Bull 64: 119-125

McArdle CS, Hole DJ (2004a) Emergency presentation of colorectal cancer is associated with poor 5-year survival. Br J Surg 91: 605-609

McArdle CS, Hole DJ (2004b) Influence of volume and specialization on survival following surgery for colorectal cancer. Br J Surg 91: 610-617

McArdle CS, McMillan DC, Hole DJ (2003) Male gender adversely affects survival following surgery for colorectal cancer. Br J Surg 90: 711-715

McMillan DC, Sattar N, McArdle CS (2006) ABC of obesity. Obesity and cancer. BMJ 333(7578): $1109-1111$

Mulcahy HE, Patchett SE, Daly L, O’Donoghue DP (1994) Prognosis of elderly patients with large bowel cancer. Br J Surg 81: 736-738

Shankar A, Taylor I (1998) Treatment of colorectal cancer in patients aged over 75. Eur J Surg Oncol 24: 391-395

Wong ND, Pio J, Valencia R, Thakal G (2001) Distribution of C-reactive protein and its relation to risk factors and coronary heart disease risk estimation in the National Health and Nutrition Examination Survey (NHANES) III. Prev Cardiol 4: 109-114 